\title{
A comparison of enzymatic degradation of myo- and scyllo- inositol hexaskisphosphate
}

TONy Hollenback ${ }^{1 *}$ MingJing SuN ${ }^{1,2}$ CHARles BREARLEY $^{3}$ AND DEB JAISI ${ }^{1}$

${ }^{1}$ Department of Plant and Soil Science, University of Delaware, Newark, Delaware (*correspondence: tonyh@udel.edu)

${ }^{2}$ Department of Physical Sciences, Emporia State University, Emporia, Kansas

${ }^{3}$ School of Biological Sciences, University of East Anglia, Norwich, UK

\begin{abstract}
Inositol phosphates are the most dominant form of organic phosphorus compounds in soils. Four stereoisomers of inositol hexakisphosphate ( $\mathrm{IP}_{6}$ ) (myo-, scyllo-, D-chiro-, and neo-) are known to exist in the environment, with myo$\mathrm{IP}_{6}$ being the most common. Inositiol hexakisphosphates are less labile than other organic $\mathrm{P}$ compounds and hence accumulate in the environment, with scyllo- $\mathrm{IP}_{6}$ presumed to be more recalcitrant than myo- $\mathrm{IP}_{6}$. Understanding the relative rates of degradation of various stereoisomers allows quantification of their relative impacts on water quality. We employed ion chromatography and NMR methods to quantify the products of scyllo-inositol hexakisphosphate degradation in the presence of phytase enzymes (from Apergilus niger and wheat) and to compare the degradation pathways to those of myo-IP ${ }_{6}{ }^{1}$. Based on the decay characteristics and isomer composition, our data supports the working hypothesis that scyllo-IP 6 decays more slowly than myo-IP 6 under the same conditions. Furthermore, the products of scyllo- $\mathrm{IP}_{6}$ degradation are unique to those of myo-IP6. Additional degradation studies on other enzymes including enzyme specificity of different stereoisomers are underway. These findings fill in knowledge gaps regarding the environmental fate and residence time of these common organic phosphorus compounds.
\end{abstract}

[1] Sun et al. (2017) Soil Sci. Soc. Am. J. 81, 61-75 